\title{
The Christmas season as a risk factor for chronic obstructive pulmonary disease exacerbations
}

\author{
Neil W Johnston MSc${ }^{1}$, Andrew Mclvor MD MSc ${ }^{1}$, Kim Lambert Reg N MSc ${ }^{1}$, Justina M Greene Dip Comp Sys ${ }^{1}$, \\ Pat Hussack Reg N1, Maria Gerhardsson de Verdier MD PhD², Tim Higenbottam MD DSc ${ }^{3}$, Jonathan Lewis BSc ${ }^{3}$, \\ Paul Newbold $\mathrm{PhD}^{3}$, Athula Herath $\mathrm{PhD}^{4}$, Martin Jenkins BA CASM ${ }^{4}$
}

\begin{abstract}
NW Johnston, A McIvor, K Lambert, et al. The Christmas season as a risk factor for chronic obstructive pulmonary disease exacerbations. Can Respir J 2010;17(6):275-281.
\end{abstract}

BACKGROUND: Epidemics of hospitalization for chronic obstructive pulmonary disease (COPD) occur annually during the Christmas holidays, and COPD exacerbations commonly coincide with respiratory viral infections.

OBJECTIVE: To compare the incidence and determinants of COPD exacerbations occurring between the Christmas holiday period and the remainder of the winter season.

METHODS: Seventy-one subjects with COPD of mixed severity faxed daily symptom diaries to a computer monitoring system from December 1 , 2006, to April 30, 2007. Possible exacerbations prompted a home visit for assessment, spirometry and specimen collection for virological testing.

RESULTS: Study subjects submitted a total of $95.4 \%$ of possible daily symptom diary sheets by fax. Of 114 possible COPD exacerbations detected using the faxed diaries, 110 met the Anthonisen criteria for true exacerbations. A total of 47 exacerbations (mean 6.7/week) occurred during the Christmas holiday period, while 63 exacerbations (mean 4.3/week) occurred during the remainder of winter. Of the Christmas period exacerbations and of those in the balance of winter, 21 (44\%) and 20 (32\%), respectively, coincided with respiratory viral infections.

CONCLUSIONS: The incidence of COPD exacerbations during the Christmas period was greater than during the rest of winter in 2006/2007 and peaked immediately before Christmas - in contrast to hospital presentation for COPD, which peaked during the Christmas week. No clear role of respiratory viral infections in the increased rate of exacerbations during the Christmas period was established in the present study. COPD patients were highly compliant with daily symptom reporting using faxed daily diaries, which permitted nearly complete detection of all exacerbations that occurred at incidence.

Key Words: Christmas; COPD; Epidemiology; Respiratory viruses

\section{La saison des fêtes comme facteur de risque d'exacerbation de la maladie pulmonaire obstructive chronique}

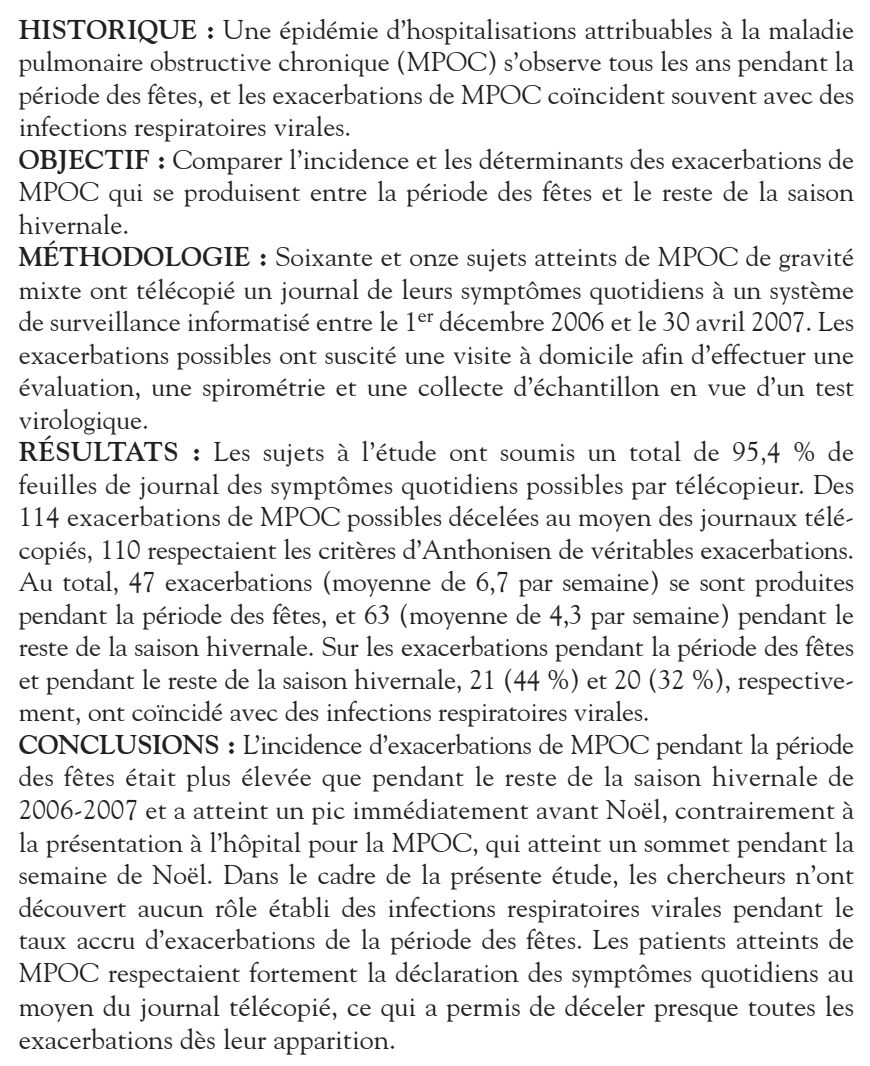

been shown to be precisely synchronized with the return to school following the summer vacation (16-18). We hypothesized that because the Christmas holiday period is one of extraordinary social interaction, it may, similar to the period following the return to school, provide opportunities for the transmission of respiratory viruses and a consequent increased risk of exacerbations in COPD patients.

Paper-based diaries and reliance on study subjects to report possible COPD exacerbations have been shown to achieve detection of one-third to one-half of these at their inception (19-22). We examined whether enabling COPD patients to record and transmit daily symptom data to a central monitoring system using fax machines would increase the likelihood of timely exacerbation detection and patient assessment.

with rhinovirus infections in children and young adults, have

${ }^{1}$ Firestone Institute for Respiratory Health, McMaster University, Hamilton, Ontario; ${ }^{2}$ Respiratory and Inflammation Therapy Area, AstraZeneca, Lund, Sweden; ${ }^{3}$ Respiratory and Inflammation Therapy Area, AstraZeneca Charnwood, Loughborough; ${ }^{4}$ Biostatistics, AstraZeneca, Alderley Park, Macclesfield, United Kingdom

Correspondence: Mr Neil W Johnston, Firestone Institute for Respiratory Health, St Joseph's Healthcare, 50 Charlton Avenue East, Hamilton, Ontario L8N 4A6. Telephone 905-522-1155 ext 33286, fax 905-628-6101, e-mail njohnsto@mcmaster.ca 


\section{METHODS}

The present study was approved by the Research Ethics Board of St Joseph's Healthcare, Hamilton, Ontario.

\section{Study design}

The present study was a prospective observational study of a cohort of COPD patients of mixed disease severity.

\section{Setting}

Subjects were recruited from specialist medical practices and directly from the community in the city of Hamilton.

\section{Subject inclusion criteria}

Patients were eligible to participate in the present study if the following criteria were met: 40 years of age or older; current or ex-smoker with a 10 pack-year or longer history; physician diagnosis of COPD; one or more emergency department (ED) visits in the previous year for respiratory symptoms; willing to provide informed consent; no significant comorbidity or disability; expected to survive for more than six months; resident in own domicile with wired telephone service; and the ability to communicate in English. Subjects meeting the above criteria underwent an assessment including clinical history, spirometry, the calculation of a BODE index (Body mass index, airflow Obstruction, Dyspnea and Exercise capacity), completion of the Chronic Respiratory Questionnaire, provision of sputum samples and nasal brushings for virological testing, and collection of blood for the measurement of $\mathrm{C}$-reactive protein (CRP) titre.

During the study period, medical care of the subjects remained with their own physicians.

\section{Data collection and detection of symptom exacerbations}

Study subjects transmitted daily diary sheets (Appendix 1) using fax machines (Intellifax-775, Brother, USA) installed in their homes. The diary sheets were automatically read into a database programmed to alert staff when one or more symptoms increased by two levels of severity; any symptom level reached level 4 or 5 (worst); the patient reported a health system encounter for a respiratory problem; the patient reported symptoms of a respiratory infection (runny or congested nose, change in phlegm colour or stickiness, sore throat, fever, shivers, wheeze, chest congestion or feeling unwell); the patient had not transmitted two sequential diary forms or the patient wrote a message to the study team on the form. Study staff telephoned patients if the above symptom levels occurred on two consecutive days or if any of the other conditions were met. Subjects in whom a COPD exacerbation was suspected were scheduled for a visit in their home from one of the study nurses as soon as possible, and questioned about recent activities, exposures and medications ordered during the exacerbation. Subjects underwent spirometry (SpiroPro, ViaSys Healthcare, USA), and had sputum specimens and nasal brushings collected for virological analysis.

During hospitalizations, the staff visited the subject as soon as medically acceptable either in hospital or, following discharge, in the subject's home.

\section{Assessment of exacerbations}

The length of COPD exacerbations and their severity according to the Anthonisen criteria (23) were assessed retrospectively by a COPD nurse who was not otherwise participating in the study. Exacerbation length was defined as the period between the date on which the symptoms of a cold were first reported by the subject or, if not applicable, the date of an encounter and the date the patients' symptoms returned to preexacerbation levels. In all cases, the decision to initiate an encounter was triggered by a subject confirming to staff that they had a cold or were experiencing an exacerbation.

\section{ED data}

To determine the patterns of ED visits for COPD in Hamilton during the study period, data for all presentations to an ED with a primary diagnosis of COPD (based on International Classification of Diseases, 10th Revision [ICD-10] codes J40 to J44 and J47) for residents 40 years of age or older between December 1, 2006, and March 31, 2007 (data not available for April 2007) were obtained from the Canadian Institute for Health Information.

\section{Population virus detection data}

Data regarding respiratory viruses, including rhinovirus detected at the Hamilton Public Health Laboratory during the study period, were obtained from Health Canada (Ottawa, Ontario).

\section{Data analysis}

The Christmas COPD epidemic period was defined as December 1, 2006 to January 17, 2007, which included the period of frequent social activity before Christmas and celebrations such as those of the Orthodox Christmas in early January.

Each study subject was placed into one of three strata based on Global initiative for chronic Obstructive Lung Disease (GOLD) severity levels (24): 0, 1 and 2, or 3 and 4. The primary analysis compared the weekly rates of COPD exacerbation during the Christmas period (December 1 to January 17) and the rest of winter (January 18 to April 30). The weekly occurrence of exacerbation events was modelled using a generalized linear mixed-effect model (binomial). The subjects were modelled as a random effect, while the Christmas period (yes/no), age at enrollment and disease severity (GOLD stratum) were modelled as fixed effects.

Kaplan-Meier curves were calculated to show differences between the three GOLD level strata in the time to first exacerbation. The Fisher's exact test was used to detect differences between study periods in the frequency of RVIs coinciding with exacerbations. A linear mixed-effects model with random effect for subject was used to examine the differences between postbronchodilator forced expiratory volume in $1 \mathrm{~s}$ $\left(\mathrm{FEV}_{1}\right)$ as a percentage of predicted $\mathrm{FEV}_{1}$ at baseline assessment and during exacerbations. Only subjects who experienced exacerbations were included in the analysis.

\section{Microbiological testing}

Of primary interest was the possibility of an increased risk of RVIs in COPD patients during the Christmas period. Accordingly, specimens were not tested for bacterial infection. Virological testing was performed using polymerase chain reaction techniques that have been previously described (25). Sputum and nasal fluid specimens were tested separately to detect picornaviruses including rhinoviruses, enteroviruses, coronaviruses 229E and OC43, respiratory syncytial virus, influenza $\mathrm{A}$ and $\mathrm{B}$, adenoviruses, parainfluenza viruses 1 to 3 , human metapneumovirus, bocavirus, Mycoplasma pneumoniae and Chlamydia pneumoniae. 
TABLE 1

Demographic and clinical characteristics of the study population

\begin{tabular}{|c|c|c|c|}
\hline \multirow[b]{2}{*}{ Characteristics } & \multicolumn{3}{|c|}{ GOLD stratum } \\
\hline & 0 & 1 and 2 & 3 and 4 \\
\hline Age, years, median (interquartile range) & $58.4(10.3)$ & $65.8(18.0)$ & $65.9(13.2)$ \\
\hline Smoking, pack-years, median (interquartile range) & $40.0(29.5)$ & $51.3(40.3)$ & $48.0(26.3)$ \\
\hline Current smokers, n (\%) & $12(48)$ & $7(30)$ & $4(17)$ \\
\hline BODE index score & $2.3 \pm 2.2$ & $2.3 \pm 1.8$ & $5.6 \pm 2.5$ \\
\hline Per cent predicted $\mathrm{FEV}_{1}$ at baseline & $82 \pm 18$ & $66 \pm 19$ & $35 \pm 9$ \\
\hline 6 min walk distance, $\mathrm{m}$ & $353 \pm 156$ & $405 \pm 105$ & $328 \pm 168$ \\
\hline Body mass index, kg/m² & $29.0 \pm 8.5$ & $29.0 \pm 5.4$ & $25.9 \pm 6.1$ \\
\hline Emergency department visits in previous year & $1.6 \pm 0.9$ & $1.4 \pm 0.7$ & $1.8 \pm 0.9$ \\
\hline Hospitalizations in previous year, $\mathrm{n}$ & $1.3 \pm 0.7$ & $1.2 \pm 0.5$ & $1.5 \pm 0.6$ \\
\hline C-reactive protein titre, $\mathrm{mg} / \mathrm{L}$ & $5.1 \pm 6.0$ & $5.0 \pm 4.8$ & $3.5 \pm 3.8$ \\
\hline Combination inhaled corticosteroid and long-acting beta- 2 agonist & $15(60)$ & $12(52)$ & $17(74)$ \\
\hline Anticholinergics including tiotropium and ipratropium/albuterol & $12(48)$ & $16(70)$ & $19(83)$ \\
\hline Oral steroid & $4(16)$ & $1(4)$ & $4(17)$ \\
\hline Leukotriene antagonist & $2(8)$ & $3(13)$ & $3(13)$ \\
\hline Theophylline & $0(0)$ & $0(0)$ & $1(4)$ \\
\hline
\end{tabular}

Data presented as mean $\pm S D$ unless otherwise indicated. BODE Body mass index, airflow Obstruction, Dyspnea and Exercise capacity; FEV ${ }_{1}$ Forced expiratory volume in $1 \mathrm{~s}$; GOLD Global initiative on chronic Obstructive Lung Disease

CRP analyses were conducted in the clinical laboratories of St Joseph's Healthcare.

\section{RESULTS}

One hundred fifty-nine subjects were screened for possible study entry between October 1 and November 30, 2006. Thirty-eight subjects were found to be ineligible and 50 declined to participate; thus, 71 were recruited. Two of the 71 subjects died during the study period. There were no dropouts. On average, GOLD stage 0 subjects were seven years younger, more likely to be female and more likely to be current smokers than those in the two other GOLD strata (Table 1). Subjects with severe disease (GOLD 3 and 4) had higher BODE scores than subjects in the other strata. The groups were comparable in most of the other characteristics examined including the number of previous hospital treatments for COPD exacerbation episodes.

\section{Daily diary data}

Subjects submitted a total of $95.4 \%$ of the possible daily questionnaires. Subject reasons for nonsubmission were hospitalization, technical difficulties and vacations. No diary data were collected during hospitalization episodes (130 subject days) and these data were not included in the total days for the calculation of diary compliance. During the study period, hospitalizations excepted, daily diary forms were submitted for more than $99 \%$ of possible entries, $95.4 \%$ by subjects alone and $4.5 \%$ with assistance from the study staff.

A total of 114 patient encounters were initiated for apparent COPD exacerbations. Of these, 109 were determined retrospectively to have truly been for COPD exacerbations meeting the Anthonisen criteria. In one further episode, for which symptom data were not available, the subject was hospitalized and was ordered courses of oral prednisone and antibiotics; this episode was included as an exacerbation. The remaining four encounters involved apparent respiratory tract infections without concomitant changes in COPD symptoms and were not included in the data analyses. The characteristics of the 110 confirmed exacerbations are shown in Table 2. One apparent exacerbation, not included in the analyses, apparently occurred while a subject was on vacation and unable to fax daily diaries.

The number of exacerbations experienced by subjects in the three GOLD strata (Table 2) was similar, as was their severity according to Anthonisen score, the proportion coinciding with an RVI and the average length of time from inception to resolution. Subjects in the GOLD 3 and 4 group were more likely to be prescribed an antibiotic or oral steroid during an exacerbation, and have their breathing not return to normal by the end of the study period. In the GOLD 0 group, the per cent predicted $\mathrm{FEV}_{1}$ declined by an average of $7 \%$ from baseline during exacerbations $(\mathrm{P}=0.006)$, while it declined by $3 \%$ in the GOLD 1 and 2 group $(\mathrm{P}=0.26)$ and by $0.3 \%(\mathrm{P}=0.86)$ in the GOLD 3 and 4 group.

The severe stratum (GOLD 3 and 4) experienced a shorter time from study inception to their first exacerbation compared with the other two groups (Figure 1).

The highest rate of exacerbation incidence occurred in week 3 of the study (December 15 to 21) (Figure 2). The number of exacerbations in progress remained high during the Christmas week (December 22 to 28); however, no new exacerbations were detected until the following week.

\section{Results of the primary analysis}

Study participants experienced the onset of 47 COPD exacerbations - an average of 6.7 per week - during the Christmas 
TABLE 2

Encounters initiated and chronic obstructive pulmonary disease exacerbation characteristics

\begin{tabular}{|c|c|c|c|}
\hline & \multicolumn{3}{|c|}{ GOLD stratum } \\
\hline & 0 & 1 and 2 & 3 and 4 \\
\hline Encounters initiated, subjects, n (\%) & $39(25)$ & $31(23)$ & $44(23)$ \\
\hline \multicolumn{4}{|l|}{ Exacerbations according to Anthonisen type, n (\%) } \\
\hline 2 & $11(30.6)$ & $9(30.0)$ & $17(38.6)$ \\
\hline 1 (most severe) & $18(50.0)$ & $11(36.7)$ & $20(45.5)$ \\
\hline 0 & 4 & 7 & 4 \\
\hline 1 & 13 & 5 & 7 \\
\hline 2 & 3 & 7 & 3 \\
\hline 3 & 2 & 4 & 7 \\
\hline 4 & 3 & 0 & 2 \\
\hline \multicolumn{4}{|l|}{ Exacerbations requiring the following: } \\
\hline \multicolumn{4}{|l|}{ Exacerbation } \\
\hline Length $^{\star}$, days (mean $\pm \mathrm{SD}$ ) & $10.1 \pm 5.5$ & $8.8 \pm 5.2$ & $11.1 \pm 6.7$ \\
\hline Length, days, virus positive (mean $\pm S D$ ) & $11.4 \pm 6.3$ & $9.6 \pm 5.3$ & $13.3 \pm 7.3$ \\
\hline Length, days, virus negative (mean $\pm \mathrm{SD}$ ) & $9.3 \pm 5.0$ & $8.4 \pm 5.2$ & $9.8 \pm 6.3$ \\
\hline Unresolved (no return to normal breathing), n (\%) & $4(11)$ & $3(10)$ & $10(24)$ \\
\hline With prednisone prescription, $\mathrm{n}(\%)$ & $10(27)$ & $8(26)$ & $17(40)$ \\
\hline With antibiotic prescription, $\mathrm{n}(\%)$ & $13(35)$ & $18(58)$ & $30(71)$ \\
\hline With virus detection, $\mathrm{n}(\%)$ & $13(35)$ & $11(35)$ & $17(40)$ \\
\hline Per cent postbronchodilator decline in $\mathrm{FEV}_{1}$ at exacerbation from baseline, mean & 7.11 & 2.55 & 0.27 \\
\hline
\end{tabular}

*Data from 91 exacerbations, for which there was no return to 'normal breathing' in 19. FEV ${ }_{1}$ Forced expiratory volume in 1 s; GOLD Global initiative for chronic Obstructive Lung Disease

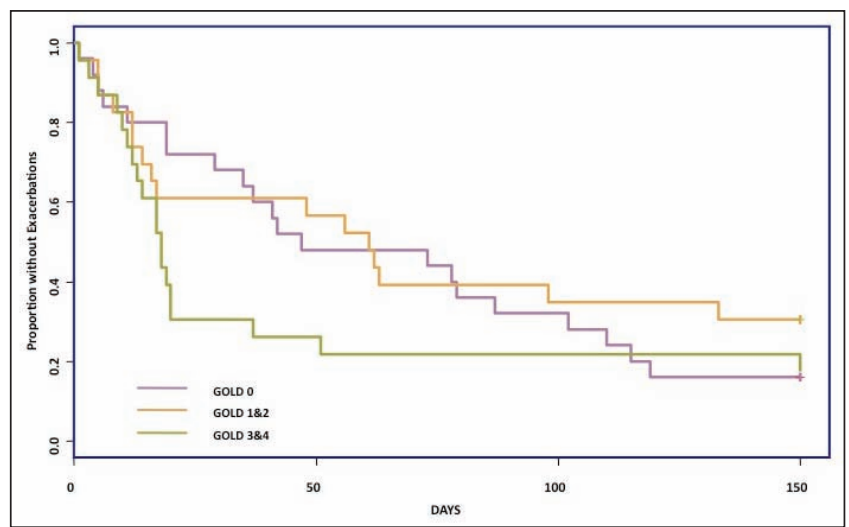

Figure 1) Kaplan-Meier curves of the time from study inception (December 1, 2006) to first exacerbation of chronic obstructive pulmonary disease. GOLD Global initiative for chronic Obstructive Lung Disease

period (December 1 to January 17). The other 63 patients averaged 4.3 COPD exacerbations/week, which occurred during the remainder of the study period (January 18 to April 30) - a statistically significant difference in weekly frequency $(\mathrm{P}=0.03)$. Twenty-one (44\%) of the Christmas period exacerbations coincided with RVIs, compared with 20 (32\%) that occurred during the rest of the study period $(\mathrm{P}=0.23)$. The time to resolution of an exacerbation during the Christmas period was 10.6 days compared with 9.6 days during the rest of the study period; this difference was not statistically significant

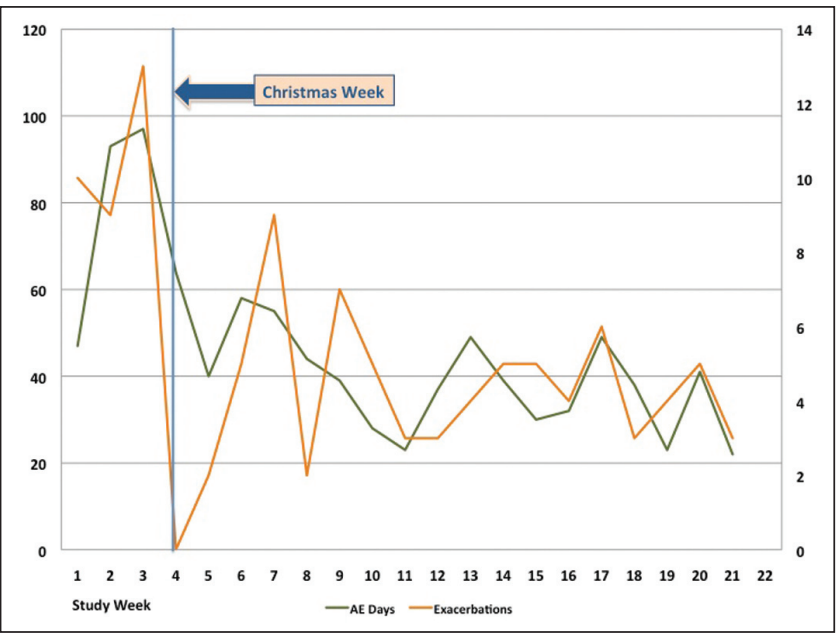

Figure 2) Incidence and prevalence of chronic obstructive pulmonary disease exacerbations in all study subjects according to the week of the study. Number of acute exacerbations of chronic obstructive pulmonary disease beginning per study week (orange line, right vertical axis) and the number of days in each study week in which acute exacerbations were occurring (green line, left axis). The vertical line shows the Christmas week (December 22 to 28)

nor was any significant difference found between the time to resolution, regardless of whether the exacerbations coincided with RVIs. The characteristics of the exacerbations that were experienced during the two study periods are shown in Table 3. 
TABLE 3

Characteristics of chronic obstructive pulmonary disease exacerbations during the Christmas period (December 1, 2006 , to January 17,2007 ) and the remainder of winter

\begin{tabular}{lcc}
\hline & $\begin{array}{c}\text { Christmas } \\
\text { period }\end{array}$ & $\begin{array}{c}\text { Remainder of } \\
\text { winter }\end{array}$ \\
\hline Exacerbations, $\mathrm{n}$ & 47 & 63 \\
Rate, per 100 subject days & 1.42 & 0.89 \\
According to Anthonisen type, $\mathrm{n}(\%)$ & & \\
3 & $7(15)$ & $17(27)$ \\
2 & $17(36)$ & $20(32)$ \\
1 (most severe) & $23(49)$ & $26(41)$ \\
According to GOLD stratum, $\mathrm{n}(\%)$ & & \\
0 & $15(32)$ & $21(33)$ \\
1 and 2 & $10(21)$ & $20(32)$ \\
3 and 4 & $22(47)$ & $22(35)$ \\
Requiring physician visit, $\mathrm{n}(\%)$ & $18(38)$ & $21(33)$ \\
Requiring ED treatment $\mathrm{n}(\%)$ & $2(4)$ & $5(8)$ \\
Requiring hospitalization, $\mathrm{n}(\%)$ & $5(11)$ & $6(10)$ \\
Length*, days (mean \pm SD) & $10.6 \pm 6.2$ & $9.6 \pm 5.8$ \\
Length, virus positive, days (mean $\pm \mathrm{SD})$ & $12.7 \pm 6.1$ & $10.2 \pm 6.7$ \\
Length, virus negative, days (mean $\pm \mathrm{SD})$ & $8.9 \pm 5.9$ & $9.3 \pm 5.3$ \\
With prednisone prescription, $\mathrm{n}(\%)$ & $14(28)$ & $19(32)$ \\
With antibiotic prescription, $\mathrm{n}(\%)$ & $25(53)$ & $33(52)$ \\
With virus detection, $\mathrm{n}(\%)$ & $21(44)$ & $20(32)$ \\
\hline
\end{tabular}

*Data from 91 exacerbations, for which there was no return to 'normal breathing' in 19. GOLD Global initiative for chronic Obstructive Lung Disease; ED Emergency department

Viruses associated with exacerbations

Nasal fluid samples were obtained from patients during all of the 110 confirmed COPD exacerbations, while sputum samples were obtained during 69 (63\%) COPD exacerbations. Samples from $42(38 \%)$ of the exacerbations yielded at least one respiratory virus including 24 (22\%) of the nasal specimens and 26 (38\%) of the sputum specimens (Table 4). In only four of the exacerbations was the same virus detected in both nasal fluid and sputum. In a further four exacerbations, different viruses were detected in the nasal fluid and sputum (one rhinovirus/other picornavirus, one influenza virus/rhinovirus, one respiratory syncytial virus/influenza virus and one respiratory syncytial virus/rhinovirus).

Comparison of study cohort exacerbation patterns with population ED use

The peak in ED visits for COPD for the overall population of Hamilton occurred in the two weeks from December 22, 2006, to January 4, 2007 (Figure 3), following the peak of COPD exacerbations in the study cohort, which occurred during the week of December 14 to 21 (Figure 2).

Respiratory viruses prevalent in the community during the study period (rhinovirus data not available)

During the study period (December 1, 2006 to April 30, 2007), there was a high level of weekly variation in the numbers of positive community virus detections, most of which were of influenza, parainfluenza or respiratory syncytial virus. The greatest number (209; double the count in any other study week) occurred during the week ending January 14 . Monthly peak numbers also occurred during the weeks ending December $16(\mathrm{n}=86)$, February 24 $(\mathrm{n}=111)$, March $10(\mathrm{n}=120)$ and April $14(\mathrm{n}=88)$.
TABLE 4

Viruses detected during COPD exacerbations

\begin{tabular}{lcc}
\hline Virus & $\begin{array}{c}\text { Nasal fluid } \\
(\mathbf{n}=\mathbf{1 1 0})\end{array}$ & $\begin{array}{c}\text { Sputum } \\
(\mathbf{n}=69)\end{array}$ \\
\hline Rhinovirus & 4 & 14 \\
Other picornavirus & 2 & 3 \\
Respiratory syncytial virus & 8 & 4 \\
Influenza & 5 & 1 \\
Corona virus & 3 & 3 \\
Boca virus & 2 & 1 \\
Total & 24 & 26 \\
\hline
\end{tabular}

COPD Chronic obstructive pulmonary disease

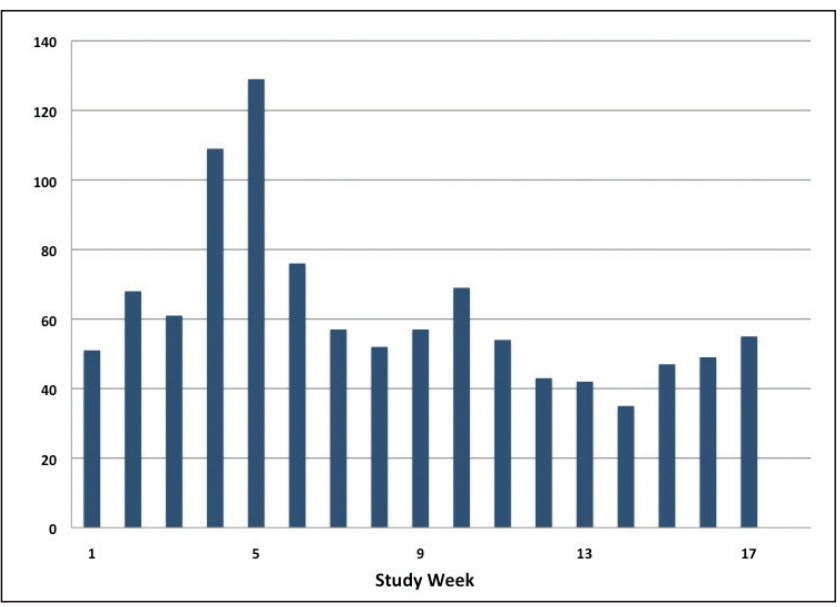

Figure 3) Emergency department visits for chronic obstructive pulmonary disease among the population of Hamilton, Ontario, from December 1, 2006, to April 30, 2007. Absolute number of emergency department visits for chronic obstructive pulmonary disease initiated by residents of Hamilton during the first 17 weeks of the study period (data for April 2007 not available). Week 5 represents December 29, 2006, to January 4, 2007

\section{DISCUSSION}

We showed that the incidence of COPD symptom exacerbations accelerated to high levels in the three weeks preceding the Christmas holiday period, and that worsened symptoms remained at high levels through the Christmas week, a peak period of hospital service use by COPD patients. Continued worsening of exacerbations that begin immediately before the holidays may, therefore, drive annual Christmas season COPD hospitalization epidemics. It is possible that a reduced level of access to usual medical care during the Christmas week may contribute to the observed higher levels of hospitalization for COPD during this time; however, it seems unlikely that it would influence symptom profiles and the inception of exacerbations. The absence of COPD exacerbation incidence during the week of December 22 to 28 was surprising and difficult to explain. It is conceivable that subjects raised their threshold for reporting symptoms during the holiday week or that unscheduled physician visits - reports of which in diaries might have triggered an encounter - did not occur. While we found that the proportion of exacerbations associated with RVIs was one-third greater during the Christmas period than during the rest of the study period, this finding may have occurred by chance; however, the intensity of Christmas COPD exacerbation peaks is highly variable between years (12) and the role of RVIs in these will require further multiple-year studies. 
Overall, 38\% of confirmed COPD exacerbations in our study coincided with RVIs, a finding comparable with those in other prospective studies of COPD patients in a community setting $(10,26,27)$. However, this figure may be an underestimate of the true proportion of exacerbations associated with RVIs in our study for the following reasons:

- More sputum than nasal fluid samples were virus positive and the same virus was rarely present in each; however, we only obtained sputum specimens in $63 \%$ of confirmed exacerbations.

- We inserted nasal swabs into one nostril only, and only as far as the subjects were comfortable with; a more aggressive approach such as nasal catheterization, may have significantly increased the rate of virus detection.

- In some cases, specimen collection was delayed because of subjects' hospitalizations, delays in fax transmission or delays in scheduling encounters.

We recognize that our fax-based COPD symptom diary had several limitations imposed, in part, by a need for brevity and readability; however, its primary purpose, the detection of COPD exacerbations at or near incidence, was achieved in all cases but one. Reports (19-22) of other well-conducted prospective studies of COPD patients using paper-based diaries and reliance on patients to contact study staff when exacerbations occur have found that one-half to two-thirds of these may not be reported. The rate of COPD exacerbations detected and assessed in our study (1.6 per subject) during a five-month high-risk period, is consistent with true annual rates found following retrospective analyses of paper-based diaries in other studies $(19,21,22)$.

When the present study was conducted, the GOLD 0 category was still in use and we aimed to study a cohort representative of all of the GOLD categories at that time. The similar frequency and apparent severity of COPD exacerbations in patients in the different GOLD strata were surprising. Our GOLD 0 subjects may not have been representative of the general population of GOLD 0 patients, possibly because all of our subjects were required to have a previous ED visit for COPD exacerbation.

We note that the number of exacerbations per week at the inception of the study was already high. It is possible that the acceleration of COPD exacerbation incidence to its peak through the Christmas period began in November - a possibility that our study was not able to examine.

\section{CONCLUSION}

The Christmas epidemic of COPD hospitalization is driven by aggravation of respiratory symptoms that begin in the preChristmas period, possibly related to social activity and increased levels of RVIs, and may be fostered by reduced access to normal primary medical care over the holiday period.

ACKNOWLEDGEMENTS: NJ led the study design team, cosupervised the conduct of the study and drafted the manuscript. AM clinically assessed study patients, led patient recruitment and co-supervised conduct of the study. KL led the study operations team, conducted patient assessment and managed patient participation. PH conducted assessment of study events and audited patient data. JG prepared and audited study data files. MG de V provided intellectual guidance throughout the study's inception, design and conduct. TH, JL and PN provided guidance and assistance with study design and result interpretation throughout. $\mathrm{AH}$ and $\mathrm{MJ}$ designed and conducted statistical analyses. All authors contributed to and reviewed the manuscript. The conduct of virological analyses in the laboratory of Professor Sebastian Johnston, Imperial College, London, United Kingdom, is sincerely appreciated.

POTENTIAL CONFLICTS OF INTEREST: NJ has received research funding and/or honoraria from Merck Frosst Canada, GlaxoSmithKline Canada, and AstraZeneca PLC (United Kingdom). AM has received consulting fees and honoraria from AstraZeneca Canada, Boehringer Ingelheim Canada, GlaxoSmithKline Canada, Nycomed Canada, and Pfizer Canada. $\mathrm{KL}, \mathrm{PH}$ and JG report no potential conflicts of interest. MG de V, JL, MJ and PN are employees of AstraZeneca PLC (United Kingdom) and may hold stock or stock options in the company. $\mathrm{AH}$ is an employee of Medimmune (United Kingdom) and may hold stock or stock options in the company. TH is an employee of Chiesi Farmaceutici, Italy.

\section{APPENDIX 1: DAILY FAX FORM}

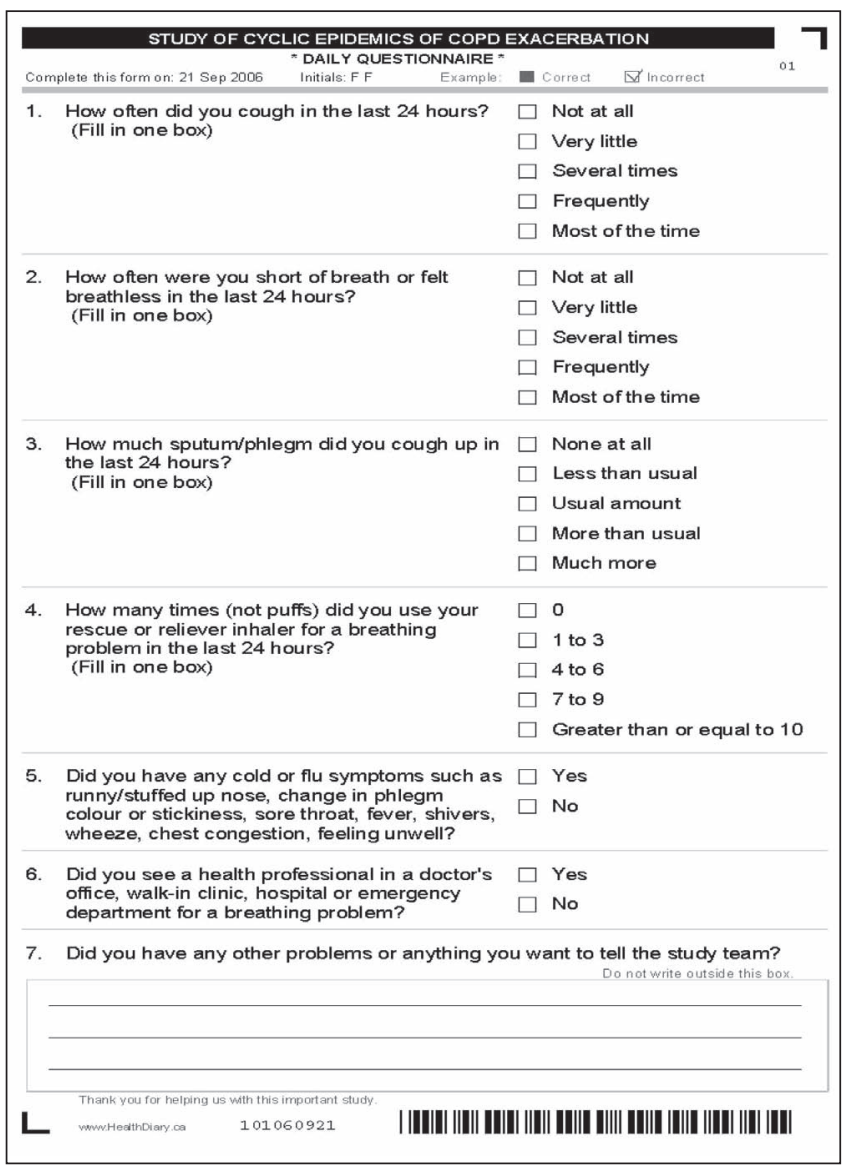

\section{REFERENCES}

1. Reichert TA, Simonsen L, Sharma A, et al. Influenza and the winter increase in mortality in the United States, 1959-1999.

Am J Epidemiol 2004;160:492-502.

2. Vilkman S, Keistinen T, Tuuponen T, et al. Seasonal variation in hospital admissions for chronic obstructive pulmonary disease in Finland. Arctic Med Res 1996;55:182-6.

3. Yap FH, Ho L, Chan PK, et al. Excess hospital admissions for pneumonia, chronic obstructive pulmonary disease, and heart failure during influenza seasons in Hong Kong. J Med Virol 2004;73:617-23. 
4. Weiss KB. Seasonal trends in US hospitalizations and mortality. J Am Med Assoc 1990;263:2323-8.

5. Donaldson GC, Wedzicha JA. COPD exacerbations 1: Epidemiology. Thorax 2006;61:164-8.

6. Johnston SL. Overview of virus-induced airway disease. Proc Am Thorac Soc 2005;2:150-6.

7. Upshur RE, Knight K, Goel V. Time-series analysis of the relation between influenza virus and hospital admissions of the elderly in Ontario, Canada, for pneumonia, chronic lung disease, and congestive heart failure. Am J Epidemiol 1999;149:85-92.

8. Rohde G, Wiethege A, Borg I, et al. Respiratory viruses in exacerbations of chronic obstructive pulmonary disease requiring hospitalisation: A case-control study. Thorax 2003;58:37-42.

9. Nicholson KG, Kent J, Ireland DC. Respiratory viruses and exacerbations of asthma in adults. BMJ 1993;307:982-6.

10. Seemungal TA, Harper-Owen R, Bhowmik A, et al. Respiratory viruses, symptoms, and inflammatory markers in acute exacerbations and stable chronic obstructive pulmonary disease. Am J Respir Crit Care Med 2001;164:1618-23.

11. Hutchinson AF, Ghimire AK, Thompson MA, et al. A community-based, time-matched, case-control study of respiratory viruses and exacerbations of COPD. Respir Med 2007;101:2472-81.

12. Johnston NW. The similarities and differences of epidemic cycles of COPD and asthma exacerbations. Proc Am Thorac Soc 2007;4:591-6.

13. Fleming DM, Elliott AJ, Nguyen-Van-Tam JS, et al. Winter's Tale: Coming to terms with winter respiratory diseases. London: Health Protection Agency, 2005.

14. Elliot AJ, Cross KW, Fleming DM. Acute respiratory infections and winter pressures on hospital admissions in England and Wales 1990-2005. J Pub Health 2008;30:91-8.

15. Strachan D, Hansell A, Nichols T, et al. Collation and comparison of data on respiratory disease. Report to the UK Department of Health, 1999. <http://www.laia.ac.uk/COLLATE/respdata.htm> (Accessed on October 22, 2010).
16. Johnston NW, Johnston SL, Duncan JM, et al. The September epidemic of asthma exacerbations in children: A search for etiology. J Allergy Clin Immunol 2005;112:132-8.

17. Johnston NW, Johnston SL, Norman GR, et al. The September epidemic of asthma exacerbations: School children as disease vectors. J Allergy Clin Immunol 2006;117:557-62.

18. Lincoln D, Sheppeard V, Morgan G, et al. Childhood asthma and return to school in Sydney, Australia. Public Health 2006;120:854-62

19. Langsetmo L, Platt RW, Ernst P, Bourbeau J. Underreporting exacerbations of chronic obstructive pulmonary disease in a longitudinal cohort. Am J Resp Crit Care Med 2007;177:396-401.

20. Vijayasaratha K, Stockley RA. Reported and unreported exacerbations of COPD - analysis by diary cards. Chest 2007;133:33-41.

21. Burge S, Wedzicha JA. COPD exacerbations: Definitions and classifications. Eur Respir J 2003;21(Suppl 41):46S-53s.

22. Miravitlles M, Ferrer M, Pont A, et al. Effect of exacerbations on quality of life in patients with chronic obstructive pulmonary disease: A 2-year follow up study. Thorax 2004;59:387-95.

23. Anthonisen NR, Manfreda J, Warren CP, et al. Antibiotic therapy in exacerbations of chronic obstructive pulmonary disease. Ann Intern Med 1987;106:196-204.

24. Pauwels RA, Buist S, Calverley PM, et al. Global Strategy for the diagnosis, management, and prevention of chronic obstructive pulmonary disease, NHBLI/WHO Global initiative for chronic Obstructive Lung Disease (GOLD) workshop summary. Am J Respir Crit Care Med 2001;163:1256-76.

25. Chauhan AJ, Inskip HM, Linaker CH, et al. Personal exposure to nitrogen dioxide $\left(\mathrm{NO}_{2}\right)$ and the severity of virus-induced asthma in children. Lancet 2003;361:1939-44.

26. Papi A, Bellettato CM, Braccioni F, et al. Infections and airway inflammation in chronic obstructive pulmonary disease severe exacerbations. Am J Respir Crit Care Med 2006;173:1114-21.

27. McManus TE, Marley A-M, Baxter N, et al. Respiratory viral infection in exacerbations of COPD. Respir Med 2008;102:75-80. 


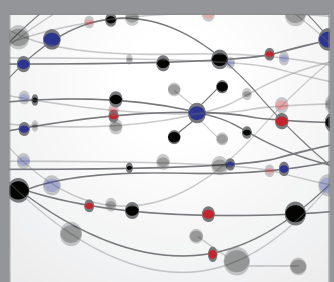

The Scientific World Journal
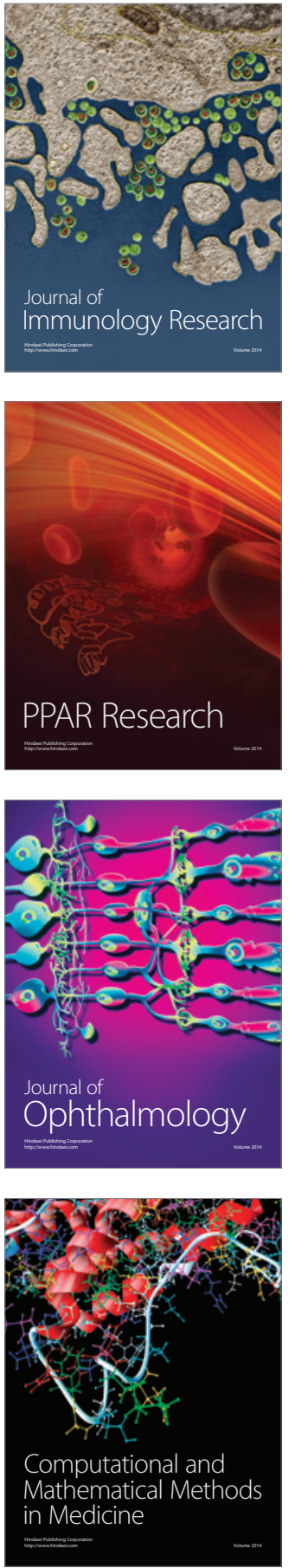

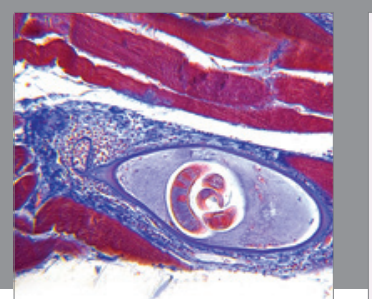

Gastroenterology Research and Practice

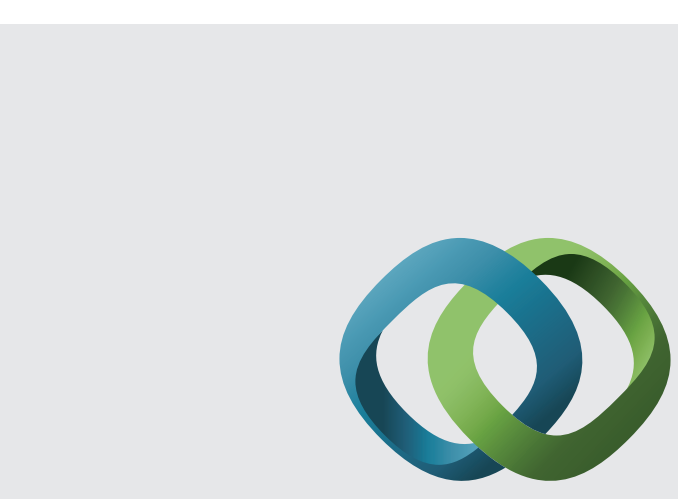

\section{Hindawi}

Submit your manuscripts at

http://www.hindawi.com
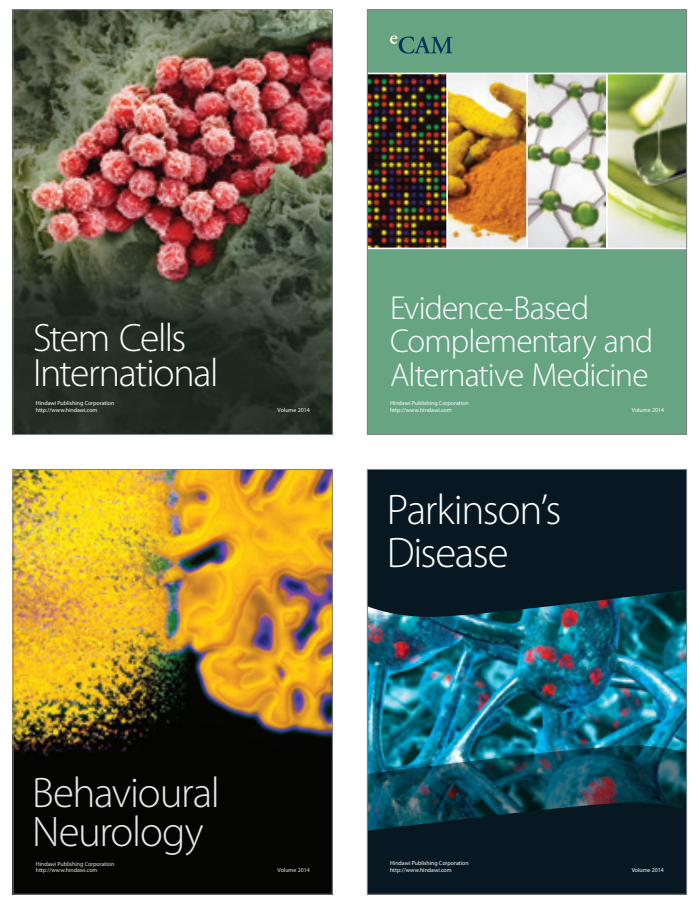
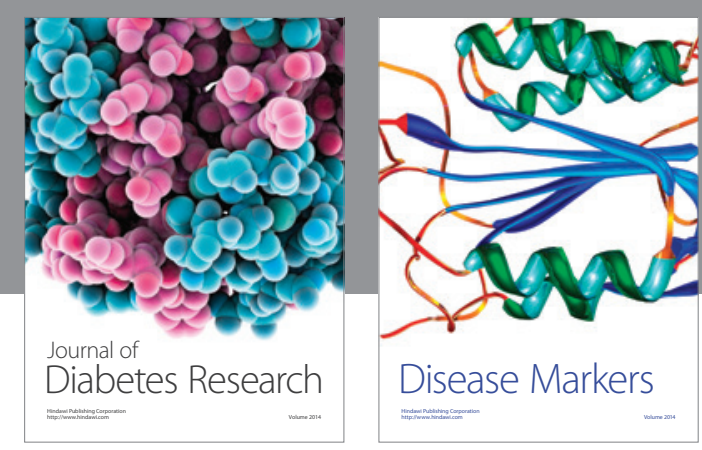

Disease Markers
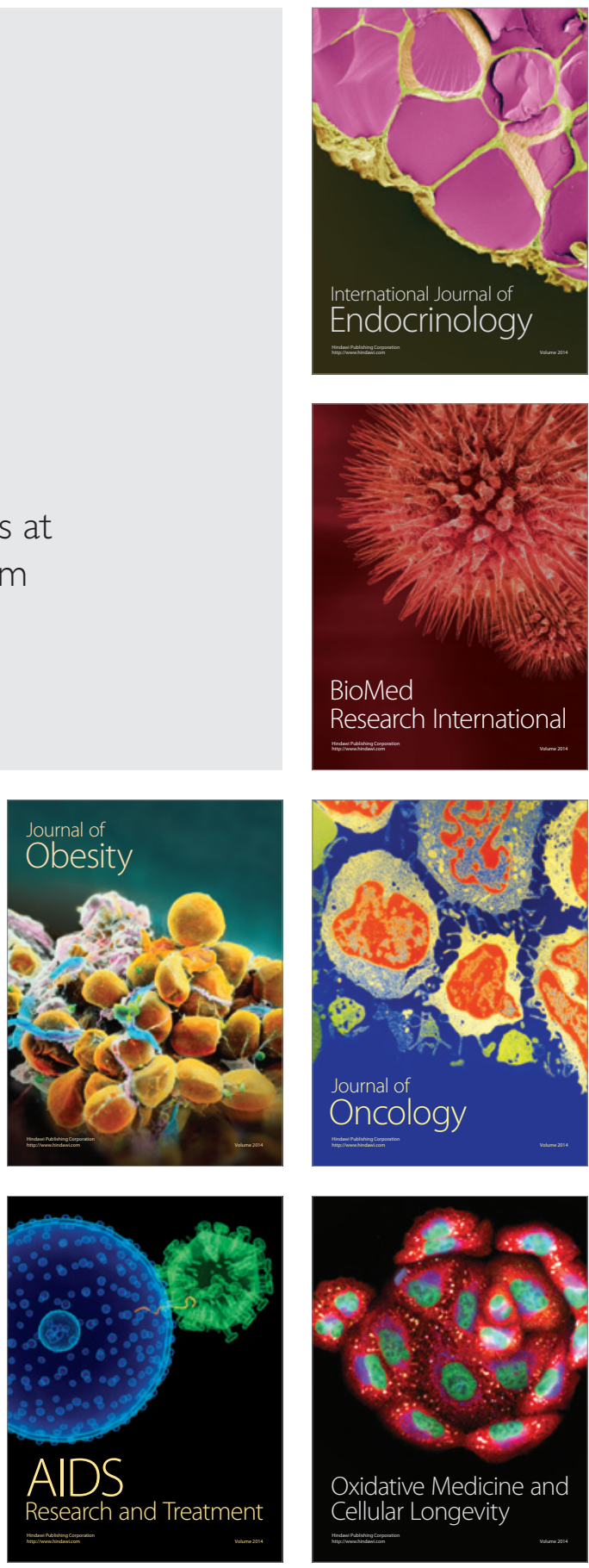